\title{
Effect of Psychological Support Intervention on Psychological Distress of Frontline Nurses during COVID19
}

\section{Sabah Abo Elftouh Mohamed,}

Assistant Professor of Psychiatric and Mental Health Nursing, Faculty of Nursing,

\begin{abstract}
Background: Psychosocial consequences of the COVID-19 pandemic may be particularly serious for nurses because of a higher level of exposure. Especially frontline nurses that are particularly at risk. Aim :The aim of this study was to evaluate the effect of psychological support intervention on psychological distress of frontline nurses exposed to COVID19.Subjects and Method: Design: The study followed a quazi experimental design. Setting: The research was conducted at Baltim isolation hospital and Qoutor general hospital which are affiliated to the Ministry of Health-Egypt. Subjects: This study's target population was made up of 50 nurses according to the inclusion criteria Tools: The study's data was gathered using two tools:"Nurse's needs and interests in dealing with COVID 19 questionnaire" and"Depression, Anxiety and Stress Scale". Results: The most of the nurses have high work pressure and don't have adequate personal protective measures, the majority of frontline nurses had sever anxiety when dealing with COVID19 patients. Also, the majority of them had moderate depression. All of frontline nurses had mild and moderate stress. The results show that there is high significant difference among studied nurse's levels of depression, anxiety and stress before and after the implementation of psychological support intervention. Conclusions: Nurses have severe psychological distress in the form of depression, anxiety and stress regarding caring of COVID19 patients, this psychological distress decreased after implementation of psychological support. Recommendation: Provide nurses with updating knowledge about the disease dimensions, vaccination and protective measures, Improve mental health, providing sufficient social support for nurses
\end{abstract}

Keywords :Frontline nurse, anxiety, stress, depression, psychological distress. 


\section{Introduction}

In January2020, the World Health Organization (WHO) announced the outbreak of a new coronavirus disease (COVID-19) to be a Public Health Emergency of International Concern, and in March2020,COVID-19 was declared a pandemic.. The high prevalence of COVID- 19 is novel and has high infectious nature in the general population of many nations, as well as high morbidity and mortality rates, putting unprecedented pressure on health-care systems around the world $^{(1)}$.

The COVID-19 epidemic has had a negative impact on mental health problems like stress, burnout, depression, and anxiety. Undoubtedly. For all healthcare staff, The coronavirus pandemic (COVID19 plays a critical role in the occurrence of psychological distress, including frontline nurses that are particularly at risk. Leads to negative mental health impacts start from worry and stress over coronavirus, nurses are at high risk to depression and anxiety. During COVID-19 pandemic the frontline nurses undertake most of the tasks related to care of the patients containment and they constitute the largest part of the healthcare worker.Nature of care of COVID-19 would be extremely stressed as a result of the changes and new ways of working $^{\cdot(2,3)}$.
Frontline nurses faced a range of psychological problems, including burnout and anxiety, which necessitated attention and assistance from organizations. ${ }^{(4)}$ The researches gave more attention for nurses' adjustment and accommodation with new ways of coping and many mental health services. Nurses are adjusting to provide care to critical cases more frequently and often in the face of more rapid deterioration than they are used to. On the other hand .Nurses often face huge psychological pressure as a result of overwhelming workload, long hours, shift duties, and working in a high-risk environment. Nurses are the frontline healthcare workers that work in acute care hospitals. Nurses' many responsibilities and duties are especially relevant during the COVID-19 pandemic because they provide health education, screening services, and assistance to the general public and high-risk individuals ${ }^{(3.4)}$.

Peer and team support is important in the direction and outlines of what administrators, departments, and leaders should do to support nurses through these critical times. The psychological contradictions between nurses' duty to care for the sick and their right to protect themselves from a potentially lethal virus 
have resurfaced as the number of COVID19 patients grows ${ }^{(5)}$.

Estimating the psychological impact of the COVID-19 outbreak on nurses is important for health authorities to develop preventive strategies and effective treatment modalities to alleviate its negative outcome. So, it is important to provide psychological support to frontline nurses to maintain nurse' psychological wellbeing.

Nurses should pay attention to their own health and meet their basic needs such as water, food, rest, and sleep, as well as scheduling rest and comfort breaks whenever possible. Keeping frontline nurses' psychological and emotional health in good shape is critical during this pandemic to play their role effectively. Indeed, improve patients' well-being, the psychological recovery measures should updated to include a place to relax, guaranteed food and daily living supplies also, access to security staff for challenging patients, as well as training to meet patients' psychological needs, during a pandemic, nurses' well-being has been prioritized

\section{Significance of the study}

Globally confirmed cases of COVID19all over the world had reached 81,475,053 with $1,798,050$ confirmed deaths On December,31, 2020, cases reported to WHO. When compared to the general population, front-line nurses were more likely to record a positive COVID-19 test, and the impact of personal protective equipment (PPE) on risk was also investigated. Frontline nurses experience negative emotions in the form of Fear and anxiety, as well as empathy for patients and family members, are both symptoms of exhaustion, pain, and helplessness. It is very important of nurses to apply selfcoping strategies, psychological adjustment and team support. Fortunately, increased affection and gratitude, professional responsibility growth, and self-reflection are all ways that nurses can grow under stress ${ }^{(9.10)}$.Finally, frontline nurses need psychological support to overcome negative emotions

\section{Aim of the Study}

The purpose of this research was to evaluate the Effect of psychological support intervention on psychological distress of frontline nurses duringCOVID19

\section{Research hypothesis}

Frontline nurses exposed to COVID19 attending psychological support intervention exhibited degree of psychological distress (stress, anxiety and depression).

\section{Subjects and Method}

Study design 
This study follow quasi experimental design.

\section{Setting}

The study was carried out at Baltim isolation hospital which is affiliated to the ministry of health it provides services 2417 weekandis specified to quarantine of COVID19 patients, 50 nurses work in this department- kafrelsheikh Governorate Egypt, and Qutor general hospital which is also affiliated also to the ministry of health and provides services 2417 week and have department of isolation of COVID19 patients at El-Gharbia Governorate- Egypt, 30 nurse work in this department.

\section{Subjects}

The study subjects were composed of 50nurses; 37 from Baltim hospital specific for COVID19 isolation and 13 nurses from Qutor general hospital isolation department.

The sample size was determined using the Epi-Info statistical software kit. The following parameters were used to determine sample size. The trust level is set at $95 \%$. (Total number of nurses who worked in study settings are 80 nurses at the time of the study).

\section{The subjects meet the following inclusion criteria \\ -Frontline nurses who provided direct treatment toCOVID-19}

- Nurses who agreed to participate in the study.

\section{Exclusion criteria}

-Nurses with psychiatric disorders.

\section{Tools of the study}

The following tools were used to collect data for the study:

\section{Tool I: Nurse's needs and interests in} dealing with COVID 19 questionnaire: $^{(11,12)}$

This tool was developed by the researcher after review literature assess the needs, interests, and problems of nurses dealing with COVID 19patients it contains :working hours, level of work pressure, rest hours, adequacy of supplies, using adequate personal protective measure, shortage in PPE and need for support . Each statement has Yes or No response.

- This tool of the study are supported by socio-demographic characteristics. of nurses ; age, sex, occupation and work setting.

Tool II: Depression, Anxiety and Stress Scale ${ }^{(14)}$

It was developed by Lovibond $\mathrm{H}$ and Lovibond F (1995). DASSIt's a set of three self-report scales for assessing depression, anxiety, and stress. Each of the three DASS-21. Scoring are classified as the following:

\begin{tabular}{|l|l|l|l|}
\hline Scoring & Stress & Anxiety & Depression \\
\hline Normal & $0-14$ & $0-7$ & \\
\hline
\end{tabular}




\begin{tabular}{|l|l|l|l|}
\hline Mild & $15-18$ & $8-9$ & $0-13$ \\
\hline Moderate & $19-25$ & $10-14$ & $14-20$ \\
\hline Severe & $26-33$ & $15-19$ & $21-27$ \\
\hline $\begin{array}{l}\text { Extremel } \\
\text { y Severe }\end{array}$ & $34+$ & $20+$ & $28+$ \\
\hline
\end{tabular}

\section{Methods}

An official permission to carry out the study was obtained from the managers of the studied settings.

\section{Ethical considerations}

- Written informed women's consent will be obtained before data collection and after explanation of the study aim.

- The collected data's confidentiality were guaranteed, as was the right to withdraw from the study at any time.

- The study did not cause harm or discomfort to the participants.

2. The researchers translated the study's tools into Arabic and had them checked for face and content validity by five experts in psychiatric and mental health nursing, with the requisite modifications made.

3. The reliability of the tools was verified by using the Arabic version of Cranach's alpha for Arabic version of Tool I and II was 0,89 and 0.95 respectively.

\section{Pilot study}

To determine the clarity and applicability of the research tools, a pilot study was conducted on a group of 5 nurses (10\%). It also sewed to estimate the estimated time needed for data collection as well as identify any obstacles that could be encountered during data collection, and these subjects were later omitted from the study with no changes required.

\section{The actual study}

- The actual research study was carried out by interviewing the nurses on an individual basis via online zoom meetings in order to apply psychological support intervention. According to the nurses who ability, the sessions lasted 30 to 40 minutes. These sessions were scheduled as three sessions per week, each nurse attended a total of 5 online sessions. The data was collected over the course of four months, from July to October 2020.

Online psychological support intervention aimed to training the nurses on helpful ways to treat and cope with psychological distress and negative emotions when dealing with COVID19 patients

- Different methods and media were used including online group discussion, videos, demonstration and re-demonstration through online sessions through Zoom application.

Psychological support intervention (counseling sessions)done through the following phases:

\section{A- Assessment phase:}


- A pre-test was performed on all the selected subjects, using the study tools through individual online meeting(through zoom meetings application) to prevent transformation of infection and quarantine

\section{B- Planning Phase:}

The researcher developed the psychological support program sessions based on the results of the assessment phase and literature review (15-19)

\section{C- Implementing Phase:}

The psychological support program sessions were implemented for the studied nurses by dividing them into 10 subgroups during implement program sessions according working hours for nurses. Each sub group was composed of 5nurses. Each subgroup attended a total of 5online sessions through zoom meeting. The time of each session was within 40minutes. These sessions were scheduled as three sessions per week. The study was conducted throughout four months from July 2020 to October 2020.

The first session: focus on introduced self to the nurses; obtained oral consent(through online conversation) from them after a brief description of the study's intent and methodology, notifying them about the schedule of the program and establishing rapport.
Second session, Focused on definition and explain how COVID 19 impacts frontline nurses' mental wellbeing and how to take personal protective measures (PPE) to prevent exposure to infection and also, how to prevent psychological and physical complication like skin lesions and exhaustions, decrease rest and sleep period, and Focused onassess level of nurse's self-esteem, identify positive and negative emotion regarding COVID 19. Then ending this session by summary and giving a conclusion about session content

Third and Fourthsessions: include applyingof psychiatric first aid techniques(PFA) for nurses which aims to Supporting nurses in the Aftermath of Crisis Events and pandemic to assisting nurses in feeling secure, calm and optimistic having access to social, physical, and affective support-regaining control by being able to benefit themselves and others How do they maintain their physical and emotional well-being in the process? Prepare, Look, Listen, and Connect are the PFA action principles. To aid participants in remembering the words Look, Listen, and Connect. Assist the nurse in locating a source of therapeutic support.

Fifth session: focus on apply relaxation techniques to reduce anxiety and expose negative emotion. This session, provide 
tips for better sleep, diet, exercise habits and encourage expression of emotion and effective communication. During this session the researcher focused on problemfocused coping technique, practicing stress management and learn more about selfcare, improve personal communication; emotion-focused coping throughout using support from others and emotional ventilation also engaged on moral purpose and spirituality support activity. This techniques help nurses to face and control the fear they experienced when dealing with COVID 19 in a safe way by using mental imagery, writing, or talk with support persons.

\section{D-Evaluation phase:}

Post-test was done to evaluate the sessions via reapplication of study tools

\section{Statistical Analysis}

For coding, entering, and analyzing data, I used SPSS (version 20). For quantitative data, the spectrum, mean, SD were calculated, and descriptive statistics such as frequencies and percentages were calculated. Spearman's correlation coefficient was used to assess the relationship between the study's variables. For the purposes of interpreting significance effects, a significant was described as a $\mathrm{P}$ value of less than 0.05 .

\section{Results}

Table 1 distribution of the study subjects in relation to their socio-demographic characteristics. The table stated that the age of the studied subjects ranged from 2240years with Mean \pm 25.0400 \pm 2.76981 year. Regarding sex about half of the studied nurses were female $52 \%$. Concerning occupation most of nurses (64 $\%)$ work as nurse specialist. Regarding Working hours $62 \%$ of nurses work 12 hours per day and most of the nurses $64 \%$ have high work pressure. in relation to adequacy of supplies, about half of nurses (48\%) don't have adequate supplies. 64\% of nurses don't have Adequate personal protective measure. The most common shortage was in protective Clothes $34 \%$ and masks $40 \%$. Regarding training program, the majority of nurses did not attained training program about COVID19.

Table 2 describes the Distribution of the studied nurses in relation to their strategies around self-care and ongoing support nurses expressed to maintain their health in dealing with COVID 19. The results indicate that, regarding Source of Information, $40 \%$ of nurses acquired information through the internet and 26\% from colleagues and supervisors. In relation to coping strategies, the most common coping methods were Talk to family members $34 \%$, Listening to spiritual topics $16 \%$ and practicing sports 
18\%. In relation to $\mathrm{g}$ needs for Training, the common dealing with suspected cases, Dealing with critical and new cases, needs was using uses personal protective measures (32\%, 82\%, and $20 \%$ respectively).regarding Spiritual support, the majority of nurses' needs spiritual support (98\%)

Table 3 shows comparison of the studied nurses in relation to their level of stress, anxiety and depression among nurses before and after psychological support sessions. The results show that more than half of nurses have mild stress (54\%) and $46 \%$ have moderate level of stress while after implementation of the support program, most of the nurses have normal stress level (60\%) and 30\% have mild stress. Regarding the level of nurses anxiety, majority of studied nurses (84\%) have sever anxiety before program while most of nurses $(74 \%)$ have mild anxiety after support session. in relation to level of depression, $92 \%$ of nurses have moderate depression level before the psychological support session while $80 \%$ of them have mild depression after the sessions.

Table 4 indicates comparison between depression, anxiety and stress (DASS) of the nurses before and after the psychological support sessions. The results show that there is high significant difference of studied nurses levels of depression, anxiety and stress before and after the implementation of psychological support sessions where $\mathrm{p}$ value $=0,000$. 
Table (1): Distribution of the study subjects in relation to socio-demographic characteristics

\begin{tabular}{|c|c|c|c|}
\hline \multicolumn{2}{|c|}{ Socio -demographic and working characteristics } & $\overline{\mathrm{N}(50)}$ & $\%$ \\
\hline \multirow{2}{*}{ Sex } & Male & 24 & 48 \\
\hline & Female & 26 & 52 \\
\hline \multirow{3}{*}{ Age } & $20-30$ & 48 & 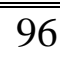 \\
\hline & $31-40$ & 2 & 4 \\
\hline & \multicolumn{2}{|l|}{$\begin{array}{l}\text { Mean } \pm \text { SD: } \\
\pm 2.76981\end{array}$} & \\
\hline \multirow{3}{*}{ Occupation } & Nursingsupervisor & 2 & 4 \\
\hline & Nursing specialist & 32 & 64 \\
\hline & Technical Nursing & 16 & 32 \\
\hline \multirow{2}{*}{ Hospital } & Isolation hospital & 37 & 74 \\
\hline & General hospital & 13 & 26 \\
\hline \multirow{3}{*}{$\begin{array}{l}\text { Number of Working hours per } \\
\text { day }\end{array}$} & 8 & 10 & 20 \\
\hline & 12 & 32 & 62 \\
\hline & 24 & 9 & 18 \\
\hline \multirow{3}{*}{ Level of work pressure } & Mild & 1 & 2 \\
\hline & Moderate & 17 & 34 \\
\hline & Sever & 32 & 64 \\
\hline \multirow{2}{*}{ Number`of rest hours per day } & 8 & 6 & 12 \\
\hline & 12 & 44 & 88 \\
\hline \multirow{2}{*}{$\begin{array}{l}\text { Availability of adequate } \\
\text { supplies }\end{array}$} & No & 24 & 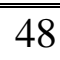 \\
\hline & Yes & 26 & 52 \\
\hline \multirow{4}{*}{$\begin{array}{l}\text { What type of supplies is un } \\
\text { available? }\end{array}$} & Medication & 5 & 10 \\
\hline & Ventilator & 11 & 22 \\
\hline & Thermometers & 11 & 22 \\
\hline & Kits & 23 & 46 \\
\hline \multirow{2}{*}{$\begin{array}{l}\text { Using Adequate personal } \\
\text { protective measure }\end{array}$} & No & 32 & $\overline{664}$ \\
\hline & Yes & 18 & 36 \\
\hline \multirow{4}{*}{ Shortage in PPE } & Mask & 20 & 40 \\
\hline & Gloves & 5 & 10 \\
\hline & Clothes & 17 & 34 \\
\hline & Eye shield & 8 & 16 \\
\hline \multirow{2}{*}{$\begin{array}{l}\text { Do you have training a program } \\
\text { about COVID19 }\end{array}$} & No & 35 & $\overline{770}$ \\
\hline & Yes & 15 & 30 \\
\hline
\end{tabular}


Table (2):strategies around self-care and ongoing support nurses expressed to maintain their health in dealing with COVID 19

\begin{tabular}{|c|c|c|c|}
\hline \multicolumn{2}{|c|}{ strategies in dealing with COVID 19} & \multirow{2}{*}{$\begin{array}{l}\mathrm{N} \\
(50)\end{array}$} & \multirow{2}{*}{$\begin{array}{l}\% \\
14.0\end{array}$} \\
\hline \multirow{2}{*}{ share Experience } & $\overline{\text { Yes }}$ & & \\
\hline & No & 43 & 86.0 \\
\hline \multirow[t]{3}{*}{ Source of Information } & Supervisor & 13 & 26.0 \\
\hline & Colleague & 13 & 26.0 \\
\hline & Internet & 24 & 48.0 \\
\hline \multirow[t]{8}{*}{ Coping strategies } & Talk to family members & 7 & 14.0 \\
\hline & - watching video & 1 & 2.0 \\
\hline & Listening to music & 2 & 4.0 \\
\hline & Listening to spiritual topics & 8 & 16.0 \\
\hline & Practicing sports & 9 & 18.0 \\
\hline & Relaxation & 2 & 4.0 \\
\hline & Meditation & 4 & 8.0 \\
\hline & Sleeping & 17 & 34.0 \\
\hline \multirow[t]{5}{*}{ Needs for training } & dealing with positive case & 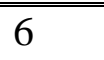 & 12.0 \\
\hline & dealing with suspected cases & 16 & 32.0 \\
\hline & Methods of prevention & 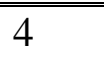 & 8.0 \\
\hline & $\begin{array}{l}\text { How to uses personal protective } \\
\text { measures }\end{array}$ & 10.0 & 20.0 \\
\hline & $\begin{array}{l}\text { Dealing with critical and emergent } \\
\text { cases }\end{array}$ & 14.0 & 28.0 \\
\hline \multirow{2}{*}{ Needing Spiritual support } & No & 1 & 2.0 \\
\hline & Yes & 49 & 98.0 \\
\hline
\end{tabular}


Table (3):Comparison of the studied nurses in relation to their level of stress, anxiety and depression among nurses before and after psychological support sessions

\begin{tabular}{|c|c|c|c|c|c|c|c|}
\hline \multirow[b]{2}{*}{ Variable } & \multirow[b]{2}{*}{ Level } & \multicolumn{2}{|l|}{ Pre } & \multicolumn{2}{|l|}{ Post } & \multicolumn{2}{|c|}{ Chi-square } \\
\hline & & $\mathrm{N}(50)$ & $\%$ & $\mathrm{~N}(50)$ & $\%$ & \multirow[b]{2}{*}{.320} & P-value \\
\hline \multirow{5}{*}{ Stress } & Normal & 0 & 0 & 30 & 60 & & \multirow[t]{5}{*}{.572} \\
\hline & Mild & 27 & 54 & 15 & 30 & \multirow{9}{*}{58.240} & \\
\hline & Moderate & 23 & 46 & 5 & 10 & & \\
\hline & Severe & 0 & 0 & 0 & 0 & & \\
\hline & Extremely Severe & 0 & 0 & 0 & 0 & & \\
\hline \multirow{5}{*}{ Anxiety } & Normal & 0 & 0 & 1 & 2 & & \multirow[t]{5}{*}{.000} \\
\hline & Mild & 0 & 0 & 37 & 74 & & \\
\hline & Moderate & 6 & 12 & 12 & 24 & & \\
\hline & Severe & 42 & 84 & 0 & 0 & & \\
\hline & Extremely Severe & 2 & 4 & 0 & 0 & & \\
\hline \multirow{4}{*}{ Depression } & Mild & 2 & 4 & 40 & 80 & \multirow[t]{4}{*}{119.760} & \multirow[t]{4}{*}{.000} \\
\hline & Moderate & 46 & 92 & 10 & 20 & & \\
\hline & Severe & 1 & 2 & 0 & 0 & & \\
\hline & Extremely Severe & 1 & 2 & 0 & 0 & & \\
\hline
\end{tabular}


Table (4):Comparison between level of depression, anxiety and stress (DASS) of the studies nurses before and after psychological support sessions

\begin{tabular}{|l|l|l|l|l|l|l|l|l|}
\hline & \multicolumn{3}{|l}{ Pre } & \multicolumn{2}{l|}{ Post } & \multicolumn{2}{l|}{ Difference } & \multicolumn{2}{l|}{ Paired T-test } \\
\cline { 2 - 9 } & Mean & SD & Mean & SD & Mean & SD & t & P-value \\
\hline Stress & $\mathbf{2 . 4 6 0 0}$ & .5034 & 1.000 & .000 & 1.46000 & $\mathbf{0 . 5 0 3 4 6}$ & $\mathbf{2 0 . 5 0 6}$ & .000 \\
\hline Anxiety & $\mathbf{3 . 9 2 0 0}$ & .39590 & 2.2200 & .46467 & 1.7000 & .58029 & 20.715 & .000 \\
\hline Depression & $\mathbf{3 . 0 2 0 0}$ & .37742 & $\mathbf{2 . 0 0 0 0}$ & .00000 & $\mathbf{1 . 0 2 0 0 0}$ & .37742 & 19.110 & .000 \\
\hline & & & & & & & & \\
\hline
\end{tabular}

\section{Discussion}

Nurses have shared the burden of COVID19 along with the rest of society, butthe majority of them have had the additional stress of working in difficult and high-risk settings. Frontline nurses faced several mental health issues during the Coronavirus Disease 2019 (COVID-19) pandemic. Indeed, Nurses in pandemics have experienced high levels of stress, anxiety and low mood with negative psychological impact. The psychological impacts on nurses have negative consequences on all organizations. There are many factors that have resulted in high psychological pressure among frontline nurses. Supporting nurses psychologically is essential to preserving psychological distress and ensuring psychological wellbeing ${ }^{(11-13)}$.

The results of the present study support the research hypothesis where the frontline nurses caring of COVID19 undergoing psychological support intervention show minimal Psychological distress (depression ,anxiety and stress) These results may be explained by the fact that normal emotional reactions in the face of a pandemic may be viewed as Stress, anxiety and depression to effect of a psychological support sessions which include stress management and anxiety reduction techniques based on nurses needs assessment, also the program sessions contained on ventilation of negative emotion and support nurses through spiritual and family members in addition to the recreational activities throughout the sessions.

Regarding to level of nurse's anxiety, the majority of frontline nurses had sever anxiety when dealing with COVID19 patients This can be speculated by the high 
negative emotions experienced by nurses during the outbreak of pandemic, then ature of pandemic and high infection rate of covid19, also the studied nurses experienced highwork pressures during a pandemic may increase their risk of burnout, and they are at risk of anxiety disorder as post-traumatic stress (PTSD).In addition to highmortality rate between health care worker and yet no vaccine or treatment for COVID19 and the disease's unknown dimensions. Also this may be due to Lack of protective measure, lack of training and need of nurses to spiritual support. Psychological support sessionhave a great effect in decreasing nurses anxiety through stress management techniques and coping strategies listening to spiritual topic and listening to music.

This result is congruent with Greenberg et al. $\mathbf{2 0 1 5}^{(22)}$ the death of COVID-19 patients caused nurses anxiety and depression, according to the researchers. This come in accordance with Greenberg et al.2015 $^{(\mathbf{2 2})}$ who reported that not all nursing staff will experience poor mental health outcomes during pandemic and hey also noted that understanding following the pandemic's height, the nursing community's psychological needs will be crucial. In this line Zhu et al. $\mathbf{2 0 2 0}^{(23)}$ reported that themajority of nurses had moderate and high levels of anxiety. Also,
Zhuet al. $\mathbf{2 0 2 0}^{(23)}$ revealed that nurses associated with COVID19 experienced high levels of stress, depression, and anxiety.

Regarding nurses depression level, the majority of nurses had problematic level of depression (moderate, sever extremely sever) toward COVID 19. This result may be due to the increasednumber of infected cases among the health care team and exposure to high risk of infection. In addition to shortage of protective measure and lack of psychological support for nurses, inability to care for patients and unavailability of treatment and vaccine. This results also may be due to the factthat COVID-19is a severe and un-predictable disease with incomplete protocols and guidelines for its management. Furthermore, that wearing protective clothing is an uncomfortable sensation that nurses must undergo on a regular basis. Nurses were forced to choose between taking care of their patients and taking care of themselves, which resulted in a struggle between fear or integrity during patient care. Thenurses' level of depression after implementation of psychological support session were mild according to theapplication of psychiatric first aid measures and techniques throughout the program sessions. 
This result is consist withSun et al.2020 (24) whofound that during an epidemic outbreak, the front-line nurses hadnegative emotions. In this lineWanget al.2020 (25) stated that medical staffwere at high risk for mental illnessduring the COVID-19 outbreak andrecommend Stress management for healthcare team dealing with COVID 19.In this stream. Hu et al.2020 ${ }^{(23)}$ confirmed that nurses experienced mild to severe depression during pandemic exposure.

This results were incongruent with Greenberg andWessely, $\mathbf{2 0 2 0}^{(22)}$ who stated that nurses who are subjected to particularly stressful or traumatic experiences show resiliency and don't suffer from chronic mental health issues symptoms such as depression, anxiety, or stress.

Regarding level of frontline nurses' stress, all had low and moderate stress level before support sessions this may be due to the lack of nurses training program for dealing with suspected cases, Dealing with critical cases, lack of personal protective measures, also, may be due to the fact that the relatively high mortality and infectious rates withCOVID-19. The death of a COVID-19 patient was traumatic for nurses. This stress level are decreased after implementation of psychological support session. This results may be due to overworked in battling a novel pandemic disease in the dangerous situation, the have work 12 hours per day, during this pandemic most of nursedifficulties in treating everyone, trying to save patients life and exhibit moral and ethical disagreements with the possibility of stress. Also, due to lack of training, the nurse trying to use coping strategies and shortage of personal protective measures and lack of using PPE by nurses.

This results in congruent with Galehdar $\mathbf{2 0 2 0}^{(\mathbf{2 1})}$, who discovered that nurses endured a variety of psychological distress when caring for COVID-19 patients. Nurses' mental health can be improved by reducing the risk factors for mental illness with adequate preparation by authorities. In the same stream,Labrague etal. ${ }^{(26)}$ andMabe $\mathbf{2 0 2 0}^{(27)}$ stated that COVID-

19 has caused increased anxiety and stress among frontline nurses. Fear and stress can be addressed, and stress levels can be reduced.

\section{Conclusion}

Based on the findings of the present study it can be concluded that the majority of frontline nurses have severe psychological distress in form of depression, anxiety and stress regarding caring of COVID19. Regarding to level of nurse's anxiety, the majority of frontline nurses had severe anxiety when dealing with COVID19 
patients. Also, the majority of nurses had moderate level of depressionduring caring with COVID 19.All of frontline nurses had moderate stress. These psychological distresses were decreased after implementation of psychological support sessions. The results show that there is high significant difference of studied nurse's levels of depression, anxiety and stress before and after the implementation of psychological support sessions.

\section{Recommendations}

Following recommendations are yielded from the result of this study:

- Establishing educational program to increase awareness regarding of preventive precautions to decrease nurses anxiety due to work pressure and work overload

- Provide services to develop mental wellness of nursesthroughavoiding and treatingphysical problems, increasing self-efficacy, offering adequate social support, and maintaining frontline job willingness.

- Provide Continuous training about wearing protective clothes and dealing with restrictions to decrease nurses' unpleasant feeling and extreme fatigue

- Provide nurses with updating knowledge about the disease dimensions , vaccination and treatment to increase nurses knowledge and awareness

- Future national and organizational strategies are required to enhance mental health during critical time by increasing self-efficacy, resilience, providing adequate social care, implementing adequate preventive measures, and maintaining nurse enthusiasm.

\section{Limitation of the study}

Future research should incorporate longitudinal study design and large sample size and to examine the results of this study's applicability.

\section{References}

1. Blake $\mathrm{H}$, Bermingham $\mathrm{F}$, JohnsonG.The psychological impact of COVID-19 onhealthcare workers: A digital learning package. International Journal of EnvironmentalResearch Public Health. 2020;17(1): 2997.

2. World Health Organization (WHO).Mental Health and Psychosocial Considerations during theCOVID-19 Outbreak. Available from:

https://www.who.int/docs/defaultsource/coronaviruse/mental-healthconsiderations.pdf (accessed on 17 April 2020). 
3. Kluge P.WHO Regional Director for Europe-Statement to the Press: Physical and Mental Health Key toResilience during COVID-19 Pandemic; WHO: Copenhagen, Denmark, 2020. Available at: https://www.euro.who.int/en/home

4. MoazzamiB,Razavi-Khorasani N, Moghadam D, Farokhi E, RezaeiaN. COVID-19 and telemedicine:Immediate action required for maintaining healthcare providers well-being.Journal of Clinical Virology.2020; 126(1): 104345.

5. AyanianZ. Mental Health Needs of Health Care Workers Providing Frontline COVID-19Care. 2020. Available from: https://jamanetwork.com/channels/heal th-forum/fullarticle/2764228 (accessed on17 April 2020).

6. Shyrock, T. COVID-19 Raises Ethical Dilemmas for Many Physicians. 2020. Available from: https://www.medicaleconomics.com/ne ws/covid-19-raises-ethical-dilemmasmany-physicians (accessed on 17 April 2020)

7. Lipley, N. Covid-19: Not a mental health crisis, healthcare experts warn.Available at:https://rcni.com/nursing-
standard/newsroom/news/COVID-19not-a-mental-health-crisis-healthcareexperts-warn-159611 (accessed on 17 April 2020).

8. Goulia P, Mantas C, Dimitroula D, Mantis D,Hyphantis, T. General hospital staffworries, perceivedsufficiency of information and associated psychological distress during the $\mathrm{A} / \mathrm{H} 1 \mathrm{~N} 1$ influenza pandemic. BMC Infection Disease.2010;10(1): 322 .

9. Chan M, HuakY. Psychological impact of the 2003 severe acute respiratory syndrome outbreak onhealth care workers in a medium size regional general hospital in Singapore.Occupational Medicine.2004; 54(1): 190-196.

10. McAlonan M, Lee M, Cheung V, Cheung C,Tsang T, Sham C,et al.Immediate and sustained psychological impact of an Emerging Infectious Disease Outbreak on health careworkers. Canadian Journal of Psychiatry. 2007;52(1): 241-247.

11. Patel S, Bachu R, Adikey A, Malik M, Shah M. Factors related to physician burnout and itsconsequences: A review.Behavior Science.2018;8(1): 98.

12. Maunder R, Hunter J, Vincent L, Bennett J, Peladeau N, Leszcz M, et al. The immediate psychological and 
occupational impact of the 2003 SARS outbreak in a teaching hospital. CMAJ. 2003; 168(1):1245-51.

13. Lu W, Wang $\mathrm{H}$, Lin $\mathrm{Y}$, Li $\mathrm{L}$. Psychological status of medical workforce during the COVID-19 pandemic:A cross-sectional study. Psychiatry Research. 2020; 288(1): 112936.

14. LovibondH,LovibondF. Manual for the Depression Anxiety and Stress Scales. $2^{\text {nd }}$ Ed. Sydney: Psychology Foundation; 1995.

15. Hogan L.The Psychological First Aid Helping Healthcare Workers through Crisis; RTÉIreland's NationalTelevision and Radio Broadcaster. 2020; Available from: https://www.rte.ie/news/coronavirus/2 020/0409/1129401-covid19-

coronavirus-mental-health-medicalstaff/(accessed on 17 April 2020).

16. American Psychological Association (APA). Combating bias and stigma related to COVID-19. March 25, 2020. Available at: https://www.apa.org/topics/covid-19bias

17. Blake H, Zhou D, Batt ME. Five year workplace wellness intervention in the NHS. Perspectives in Public Health. 2013; 133(5): 262-71. Available at: https://www.researchgate.net/publicati
on/236208506_Five_year_workplace_ wellness_intervention_in_the_NHS

18. Lai J, Ma S, Wang Y, Cai Z, Hu J, Wei N,et al. Factors associated with mental health outcomes among health care workers exposed to coronavirus disease 2019. JAMA Psychiatry. 2020; Advanced online publication February 2020 .

19. Blake H. Six ways to beat the back to work blues by building resilience. The Conversation. September, 2018. Available at: https://theconversation.com/six-waysto-beat-the-back-to-work-blues-bybuilding-resilience-102824

20. Greenberg N.NHS staff recovery plan post COVID19 (outbreak 1) Version 2. 02 May 2020. Available at: https://www.som.org.uk/NHS_staff_re covery_plan_post_COVID19_V5_out break1.pdfCUS

21. Galehdar N, Kamran A, ToulabiT,HeydariH. Exploring nurses' experiences of psychological distress during care of patients with COVID19: A qualitative study. BMC Psychiatry. 2020; 20(1):489. Available from:https://doi.org/10.1186/s12888020-02898-1

22. Greenberg N, WesselyS,Wykes T. Potential mental health consequences for workers in the Ebola Regions of 
West Africa- a lesson for all challenging environments. Journal of Mental Health. 2015; 24(1):1-3. doi: 10.3109/09638237.2014.1000676.

23. Hu D, Kongb Y, LicW, Hand Q, Zhange $\mathrm{X}$, , Zhu L . Frontline nurses'burnout, anxiety, depression, and fear statuses andtheir associated factors during the COVID-19 outbreak in Wuhan, China:A large-scale crosssectional study. E Clinical Medicine.2020; 100424.Published online $2020 \quad$ Jun 27. doi: 10.1016/j.eclinm.2020.100424 24. Sun N, Wei L, Shi S, You Y, Liu S. A qualitative study on the psychological experience of caregivers of COVID-19 patients. American Journal of Infection Control. 2020. DOI:https://doi.org/10.1016/j.ajic.202 0.03 .018

25. Wang Y, Kala M,Tazeen H. Factors associated with psychological distress during the coronavirus disease 2019 (COVID-19) pandemic on the predominantly general population: A systematic review and meta-analysis. PLOS ONE collection Education Research. 2020 December. Available from:

https://doi.org/10.1371/journal.pone.0 244630
26. Labrague E, Alexis $\mathrm{J}$. Fear of COVID-19, psychological distress, work satisfaction, and turnover intention among frontline nurses. Journal of NursingManagement. 2020; 00:1-9. Available from: https://doi.org/10.1111/jonm.13168 DOI: 10.21203/rs.3.rs-35366/v1

27. Maben J, Taylor C,Bridges J. Guidance to support nurses' psychological well-being during Covid-19 crisis. University of Surrey and the University of Southampton. April 2020. Available at: https://www.surrey.ac.uk/sites/default/ files/2020-05/guidance-to-supportnurses-psychological-well-beingduring-covid-19-crisis-final.pdf 